\title{
Need for development of low carbon economy in China using analysis of Guangdong textile industry as case study
}

\author{
Lixing Zhou* \\ Guangdong Vocational Institute of Public Administration, Guangzhou 510800, China
}

\begin{abstract}
Textile industry is a high energy-consuming industry, which depends on oil, coal and other energy resources. This paper takes Guangdong textile industry as case study and analyses its current carbon emission from the statistical yearbook. Chinese textile industry should transform and develop a low-carbon economy model. Firstly, the government should strengthen the top-level design and improve the relevant legal system. Secondly, new energy and renewable materials needs to be vigorously explored to save energy. Thirdly, the textile enterprises must speed up the industrial transformation and upgrade to enhance the added value in the industrial chain. Finally, consumers are required to update their concept of low-carbon consumption. These ways are helpful to ensure the minimization of "carbon footprint". Only by developing a circular economy and low-carbon economy, can we build a resource-saving, environment-friendly and low-carbon-oriented society.
\end{abstract}

Keywords: Low Carbon Economy; Textile industry; Transformation and development; Circular economy; Energy.

\section{Introduction}

With the increase of the world population and the continuous development of the economy, it has become an indisputable fact that the increase of carbon dioxide concentration brings about global warming. In this context, the response to global climate change has become an international action. The Climate Change Conference held in Copenhagen in 2009 brought into people's vision the "low carbon economy" model based on low energy consumption, low pollution and low emission ${ }^{[1]}$. To this end, all countries have responded positively. At the seventy-five assembly of the UN General's Carbon Summit and Carbon Neutralization, Chinese President Xi Jinping made a solemn commitment that China will reach the carbon peak on schedule by 2030 and carbon neutrality by 2060 . He highlighted it is an economic and social systemic change. Under the guidance of International Low Carbon Economy and relevant policies of our government, the low-carbon development is imperative for Guangdong textile industry to occupy the commanding heights of the national industrial development trend.

\footnotetext{
* Corresponding author: violet-815@163.com
} 


\section{Current situation of the textile industry in Guangdong}

Guangdong is a big province of light industry and textile. Since the reform and opening up, the textile industry has made rapid progress by virtue of its own location, technology, specialized production with characteristics and relatively low labor costs. Statistics from the yearbook show that in the past decade, the overall output of cloth produced by the textile industry in Guangdong Province has shown a downward trend. In 2019, the total output of cloth was 2.06 billion meters. Compared with the textile industry in other parts of the country or the world, Guangdong textile industry has absolute advantages. Now it has formed a more complete industrial system. Both of the industrial scale and product output are in the forefront of the country. In the same year, enterprises of light industry and textile industry in Guangdong Province with larger scale achieved industrial added value of 638.35 billion yuan and gained main business income of 2677.52 billion yuan, accounting for about $20 \%$ of the main business income of manufacturing enterprises in the province.

\section{Carbon emissions in Guangdong textile industry}

\subsection{General situation of energy consumption in Guangdong textile industry}

As a high energy consumption industry, the textile industry highly depends on oil, coal, natural gas, electric power and other energy resources ${ }^{[2]}$. As can be seen from Fig. 1, the total energy consumption of the textile industry in Guangdong reached an amount of 79.12 billion tons in 2008, peaking at 85.78 billion tons in 2010, after which energy consumption declined wavelike. Because before the Copenhagen Conference, the concept of ecological, environmental and sustainable development did not take root in minds. On the other hand, there is no strong laws to regulate greenhouse gas emissions. Compared to 2008, the total energy consumption of the textile industry in 2019 decreased by nearly 3 million tons. It fell by $14.5 \%$ compared with the previous year. That is the most significant decline in years. It can be seen that the carbon emission intensity of Guangdong textile industry is descending, gradually to "green GDP" development, but there is still a long way to go.

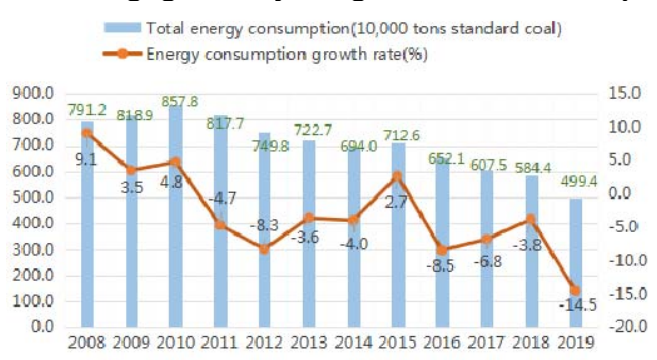

Data source: Guangdong statistical yearbook

Fig. 1. Carbon emissions in Guangdong textile industry.

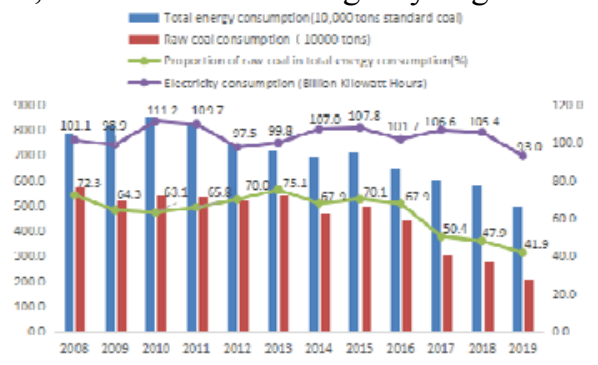

Data source: Guangdong statistical yearbook

Fig. 2. Energy consumption structure of Guangdong Textile Industry.

\subsection{Energy consumption structure of Guangdong Textile Industry}

From the perspective of energy structure, it is basically realizing the transformation from raw coal consumption as the main part and electric power as the auxiliary part to electric power consumption as the main part and raw coal as the auxiliary part. As shown in Fig. 2, before 2017, the textile industry consumed over 6 million tons of standard coal every year, 
accounting for more than $60 \%$ of the total energy consumption. The proportion of raw coal in total consumption decreased from $72.3 \%$ to $41.9 \%$. That is because the factories reduced the use of raw coal and turned to electric power, which is more cleaner. Although since 2017 , the total electric power consumption has declined, it gradually replaces raw coal and becomes the majority of energy consumption. However, Guangdong is short of energy. Power has long been supplied by the "West to East Power Transmission Project" and the Three Gorges Hydropower Station on the Yangtze River. Moreover, the power supply in Guangdong is in shortage as a whole, and peak load shifting is required during the alternation of dry season and flood season or at the peak period in summer. That is a serious problem for the future economic development of Guangdong Province.

\section{Low carbon development path of Guangdong Textile Industry}

Based on the above analysis, the textile industry is one of the industries with high energy consumption monitored by the state. The textile industry is also a huge industry with a wide range of chains, long industrial chain, many production chains, large scale differences and a large number of enterprises. In view of the fact that the energy efficiency of Guangdong Province is far less than the average level of the United States, Japan, the European Union and other developed countries, it is the only way to reduce the total amount of energy, improve energy efficiency and develop a low-carbon economy.

\subsection{Improve the relevant legal system}

At present, China's laws and regulations related to energy conservation and emission reduction mainly include "Energy Conservation Law", "Environmental Protection Law" and "Renewable Energy Law". However, these legal systems cannot meet the requirements of low-carbon economy ${ }^{[3]}$. As the top-level design of the country, the government should provide the necessary guarantee for the healthy development of low-carbon economy by formulating a sound legal system. On the other hand, the core industry chain of domestic low-carbon economic development is weak, while the relevant technology and equipment are backward. The government should actively guide the relevant enterprises by means of macro and micro controls, such as increasing financial investment. Besides, qualified textile and garment export enterprises should be encouraged to speed up transformation and strengthen the research and development of low-carbon technologies. The enterprises that do not have the basic competitiveness should be eliminated in an orderly manner.

\subsection{Vigorously develop new energy and renewable materials}

Guangdong is not rich in energy, but it is located along the coast, with strong wind and abundant light. Wind power, hydro power, geothermal power, solar power and geothermal energy,are renewable energy sources, and one of the remarkable characteristics of these energy sources is that they are renewable ${ }^{[4]}$. If the textile industry aspires to achieve low-carbon development, it needs to develop new energy. Biological energy and the above renewable energy needs to be fully excavated. Only by this way, can the textile industry gradually get rid of the high dependence on coal, oil and other traditional energy. On the other hand, some new textile printing and dyeing materials should be explored, such as regenerated cellulose fiber, functional fiber, textile fiber, etc. For example, the common modal (wood pulp fiber) and bamboo fiber on the market in recent years are all new textile fibers. The renewable resources are basically animal and plant fibers, which are more comfortable than chemical fibers. It can not only meet consumer demand, such as style and 
functionality, but also helps to reduce carbon emissions.

\subsection{Implement energy conservation, emission reduction and consumption reduction}

The global spread of "carbon label" is gradually raising the threshold of international trade, and the pressure of energy and emission reduction of the textile and garment industry is increasing. Although Guangdong textile industry is in the forefront of energy conservation and emission reduction in China, the task of energy conservation and emission reduction is also arduous ${ }^{[5]}$. There is no doubt that energy conservation and emission reduction is within the capacity of the textile industry at this stage, and also the most direct way to implement a low-carbon economy. Many textile enterprises have backward production capacity and technology, so they should take active actions to accelerate industrial transformation and upgrade, as well as vigorously advocate the use of environmental protection materials. Therefore, they can make due contributions to global environmental protection. In particular, Guangdong export-oriented economy is obvious. If the textile enterprises mainly engaging in foreign trade and export do not carry out technological innovation, they will encounter new trade barriers, such as "carbon tariff", which will be a severe threat for the textile and garment industry.

\subsection{Enhance the added value of enterprises in the industrial chain}

The textile enterprises in Guangdong Province and even the whole country are mainly processing enterprises, which are at the low end of the industrial chain and earn low processing fees. However, the environmental pollution caused by the products in the processing link is the most serious, especially in the printing and dyeing industry. By contrast, for those enterprises specializing in design and marketing, they can obtain higher income in the case of almost no carbon emissions. Therefore, China's textile and garment industry must speed up the adjustment of industrial structure, and promote industrial transformation. Undoubtedly, they need to change economic model from the traditional extensive economy to the energy-saving, environmental protection and low-carbon economy, by striving to participate in the design and marketing process. In that way, the core competitiveness of the textile industry will be enhanced from the low end of the industrial chain to the high end. On the other hand, since the implementation of "One Belt, One Road "initiative, the textile industry can rely on China's policies to focus on China's brand. It is a good choice to produce Hanfu, Tang costume and cheongsam with Chinese characteristics. It helps to enhance the brand value and upgrade the added value of the product in the production chain.

\subsection{Advocate the concept of low carbon consumption}

Today's consumer market is a buyer's market. Whether consumers are willing to buy goods or not plays a decisive role. According to statistics, a pair of Levi's jeans emits $33.4 \mathrm{~kg}$ of carbon dioxide in the whole life cycle from raw material procurement to finished products and then to final disposal, while a cotton T-shirt emits $15 \mathrm{~kg}$ of carbon dioxide. Different fabrics have different carbon emissions in the process of production and consumption. Natural fibers such as cotton and hemp are the lowest, while synthetic fabrics such as polyester and nylon are not easy to degrade and have high carbon emissions. The upgrading of consumption concept will contribute to the sustainable development of the textile and garment industry. In order to update the concept of consumption, the government needs to adopt different ways and use various mass media. The spread of the new concept makes 
people pay more and more attention to low-carbon products. Only when the public's awareness of low-carbon consumption of clothing is awakened, can they consciously resist the clothing that does not meet the ecological standards and is harmful to the body or the environment. This will help to promote the production and marketing of low-carbon development of the upstream textile industry from the "pull" perspective.

\section{Conclusion}

As is well known, China's carbon dioxide emissions are second only to those of the United States in the world. The textile industry depends highly on oil, coal, natural gas, electric power and other energy resources. These factories produce a great amount of carbon dioxide. In the face of global warming and serious shortage of resources, the textile industry needs to transform and take different ways to develop a low-carbon economy model. Firstly, the government should strengthen the top-level design and improve the relevant legal system. Secondly, the enterprises must vigorously develop new energy and biodegradable materials, further implement energy conservation and emission reduction. Next, the firms need to accelerate the industrial transformation and upgrade to enhance the added value in the industrial chain. Last but not least, consumers are required to update their concept of low-carbon consumption. In a word, the government and the textile factories as well as consumers should fully take the resource and environmental issues into consideration from product design, procurement and manufacturing to consumption and scrap. Resource-saving, environment-friendly and low-carbon oriented society will be built by means of a circular economy and low-carbon economy.

\section{Acknowledgement}

1. Project of the 13th five-year Plan for the development of philosophy and social sciences in Guangzhou in 2020, Project No.: 2020GZGJ219.

2. Guangdong Province General Colleges and universities young innovative talent category project in 2019, Project No.: 2019GWQNCX017.

3.Philosophy and social science planning project of Guangdong party school (School of administration) in 2020, Project No.: 2020GDDXXT078.

\section{References}

1. Qiannan Zhang. Research on the transformation and upgrading path of Guangdong textile industry based on low carbon economy[J]. Enterprise economy, 2013, 32(8):11-21.

2. Yuanyuan Liang. Research on the transformation of green trade under the background of low carbon economy----an analysis of Zhejiang textile industry[J]. Modern Economic Information, 2016, (8):148-149.

3. Guangyi An. Analysis on the influence of modern economic information and low carbon economy on China's textile and garment export[J]. Business Management, 2021, (1):52-53.

4. Lixing Zhou. Opportunities and challenges faced by private enterprises under the lowcarbon economy and countermeasures[C]. E3S Web of Conferences, 2021.

5. Lijie Li, Cuncun Tao. Discussion on status quo and development trend of low carbon economy of textile printing and dyeing industry[J]. Shandong Textile Economy, 2020, (9):22-24. 